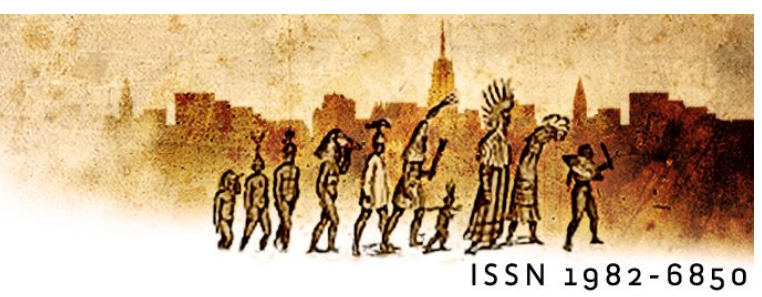

\title{
Limites da Fenomenologia da Empatia na Cognição Social
}

\author{
Daniel De Luca-Noronhai (FAJE)
}

Resumo: O debate contemporâneo sobre a cognição social tem sido marcado pela retomada da abordagem fenomenológica da empatia. Essa abordagem postula uma experiência perceptual direta com outras mentes, ao menos em situações típicas de interação. Meu objetivo neste artigo é investigar o alcance dessa tese. Tentarei mostrar que este alcance é mais limitado do que os proponentes da empatia estariam dispostos a aceitar. Ainda que haja uma experiência perceptual direta com outras mentes, essa experiência não envolve um grau de flexibilidade suficiente para o que é requerido em situações ordinárias de coordenação de ação, precisamente aquelas situações focadas pela abordagem fenomenológica. Esse problema poderá oferecer a ocasião de uma exploração futura sobre o papel de capacidades inferenciais em tais situações.

Palavras-Chave: Cognição Social; Percepção; Fenomenologia; Flexibilidade.

Abstract: The contemporary debate about social cognition has been marked by the resurgence of the phenomenological approach of empathy. This approach argues for a direct perceptual experience with other minds, at least in typical situations of interaction. My aim in this paper is to investigate the scope of this claim. I argue that its scope is more limited than the proponents of empathy would be willing to accept. Even if there is such a thing as direct perceptual experience with other minds, this experience does not involve as much flexibility as it is required in ordinary situations of coordination of actions, which are precisely the situations emphasized by the phenomenological approach. This problem might pave the way for further investigations on the role of inferential capabilities in such situations.

Keywords: Social Cognition; Perception; Phenomenology; Flexibility.

\section{Empatia e Percepção direta}

O debate contemporâneo sobre cognição social (capacidade de reconhecer outras mentes) tem sido marcado pela retomada da abordagem fenomenológica da empatia. ${ }^{1} \mathrm{O}$ objetivo dessa retomada é, basicamente, investigar um domínio do qual as teorias

\footnotetext{
${ }^{1}$ A abordagem fenomenológica da empatia remonta, entre outros, a Husserl, Scheler e Merleau-Ponty. Sobre essa herança, ver Zahavi e Overgaard (2012).
} 
tradicionais da cognição social, Teoria-teoria (theory-theory) e Teoria da Simulação, ${ }^{2}$ teriam passado ao largo. O comprometimento com uma imagem inferencialista da cognição social fez com que essas teorias prescindissem do papel da percepção no entendimento de outras mentes em situações ordinárias de interação. Uma fenomenologia da empatia, enquanto preocupa-se primordialmente com a experiência perceptual com o outro, poderia lançar luz sobre esse explanandum. Essa concepção da empatia foi proposta, entre outros, por Zahavi e Overgaard:

On the phenomenological account, empathy is not a distinct and specific emotion (like embarrassment, shame or pride), rather it denotes a basic, irreducible, form of intentionality directed at other experience subjects as such. ${ }^{3}$

Zahavi e Overgaard tomam a experiência perceptual com o outro pelo seu valor de face. Procuram, assim, fazer justiça à diferença entre, por exemplo, experienciar a dor de outra pessoa e efetivamente experienciar essa dor (em primeira pessoa). Na empatia, o intérprete está voltado para as emoções, sentimentos e pensamentos do outro. Ele não está focado em si mesmo. É bem certo que ele pode sentir, em alguma medida, o que o outro sente. Mas isso não se coloca como pré-requisito da capacidade de reconhecer, em sua experiência perceptual, os estados mentais dos outros. Essa abordagem distingue-se daquelas que afirmam ser a empatia um processo mediado por alguma outra capacidade cognitiva, digamos, extraperceptual. ${ }^{4}$

Por certo, a abordagem fenomenológica não tem qualquer comprometimento com um behaviorismo reducionista. Sua proposta consiste em fazer justiça ao caráter mental do comportamento humano. No entanto, a abordagem quer colocar em questão a ideia central assumida pelas teorias tradicionais de que estados mentais são inobserváveis. Tal crítica viria do fato de que, tipicamente, o intérprete não precisa imaginar como seria para ele se

\footnotetext{
${ }^{2}$ Para a Teoria-teoria, o intérprete se baseia em leis psicofísicas para atribuir estados mentais ao outro. Já para a teoria da simulação, essa atribuição é realizada com base nos estados mentais do próprio intérprete (voltarei a esses aspectos). A abordagem fenomenológica se posiciona no debate como uma posição alternativa em relação a essas duas teorias.

3 “Na análise fenomenológica, a empatia não é uma emoção distinta e específica (como o constrangimento, vergonha ou orgulho); mas sim, denota uma forma de intencionalidade básica e irredutível, dirigida à experiência do outro como tal." (ZAHAVI;OVERGAARD, 2012, p.04)

4 Ao menos alguma capacidade cognitiva que envolva consciência do agente. Note-se que há muitas abordagens sobre a empatia que levam em conta alguma mediação, pessoal ou subpessoal, como as de Goldman (2006), De Vignemont (2010) e Stueber (2006).
} 
estivesse na posição do outro. Tampouco é necessário um passo inferencial entre observar a ação de um agente e atribuir os estados mentais que poderiam explicar essa ação. Essa compreensão da empatia conduz, portanto, à ideia de que podemos perceber outras mentes de maneira direta.

À primeira vista, não é difícil encontrar situações em que parece plausível afirmar uma experiência perceptual direta com os estados mentais dos outros. Considere-se, por exemplo, nossa capacidade de perceber e distinguir expressões faciais como raiva, alegria ou dor. Ao que parece, não precisamos despender um esforço cognitivo, tal que ocorreria na imaginação sobre o que ocorre na mente do outro. Nem precisamos passar pela mesma experiência: diante do reconhecimento de uma expressão de raiva, podemos, por exemplo, sentir medo. Ademais não parece correto afirmar que vemos meros contornos faciais e, a partir disso, inferimos a emoção correspondente. Por fim, num exemplo mais diretamente relacionado à ação, quando observamos uma ação de agarrar um objeto, não vemos meros movimentos corporais e inferimos intenções motoras. ${ }^{5}$ Deparamo-nos já com um comportamento direcionado a fins. Assim a fenomenologia pode mostrar que, em situações típicas de interação social, não percebemos meros movimentos corporais, mas sim ações, ou um comportamento já investido de mentalidade. Nesses casos, não nos deparamos com um gap entre o comportamento e os seus respectivos estados mentais.

Se nessas ocasiões não há um gap entre mente e comportamento, como fica a imagem inferencialista da cognição social? Para os proponentes da empatia, o inferencialismo presente nas abordagens tradicionais resulta de uma imagem empobrecida do que está disponível à percepção do intérprete. ${ }^{6}$ Tanto para a Teoria-teoria quanto para algumas versões da Teoria da simulação, a percepção do comportamento dos outros é simplesmente o início de um processo inferencial, cujas premissas são leis psicofísicas (Teoria-teoria) ou os próprios estados mentais do intérprete (teoria da simulação). O ponto de chegada desse processo inferencial é a explicação ou predição do comportamento. Até que esse passo inferencial seja dado, o comportamento mantém-se opaco para o intérprete.

\footnotetext{
5 Vale a pena remeter aqui à distinção proposta, entre outros, por Pacherie (2003), entre intenções prévias e intenções motoras. Intenções prévias fornecem razões explicativas da ação, mas não possuem uma relação causal próxima com o movimento corporal, uma vez que podem ser formadas em um tempo muito anterior à ação e, além disso, podem não causar um determinado comportamento a elas prima facie associado. Já intenções motoras acompanham diretamente o movimento corporal direcionado a fins. Essa diferença será retomada adiante.

${ }^{6}$ Ver, sobre isso, a diferença entre riqueza e pobreza perceptual proposta por Gallagher (2008).
} 
Sem a operação de capacidades inferenciais, o intérprete percebe meros movimentos corporais, desprovidos de mentalidade. Entretanto, como vimos, os teóricos da empatia afirmam que não são meros estímulos físicos que se encontram disponíveis à percepção do intérprete, mas, ao que parece, um comportamento já dotado de mentalidade. Uma concepção informada ou rica da percepção deveria, portanto, colocar em questão o caráter pervasivo que tradicionalmente se atribuiu à realização de inferências na cognição social.

Não é, contudo, simples compreender como podemos ver mentes nas ações. Na medida em que os estados mentais associados ao comportamento têm caráter funcional ou motivador, é difícil mostrar de que forma eles podem figurar no conteúdo da percepção do intérprete. Há aqui um risco de se inflacionar o conteúdo da percepção. Um caminho, proposto por Joel Smith (2010), consiste em mostrar que podemos experienciar na percepção outros estados mentais ainda que eles não sejam, literalmente, vistos. Smith baseia-se no argumento fenomenológico de que o que experenciamos vai além do que efetivamente percebemos. Por exemplo, quando olho para um tomate, vejo apenas uma de suas faces. Apesar disso, tenho uma experiência com o tomate inteiro, com um objeto tridimensional. Aqui temos um traço importante da percepção: as partes ocultas do tomate estão, de forma supramodal, co-presentes na consciência perceptual. Elas se fazem presentes mediante antecipações acerca de como o objeto aparecerá se o agente desse a volta em torno dele. Tais antecipações dependem de capacidades perceptuais, não de crenças (SMITH, 2010, p. 737).

De maneira análoga, estados mentais podem estar co-presentes na experiência perceptual com os outros. Por exemplo, a dor pode estar presente mesmo se somente determinadas reações corporais são efetivamente percebidas. Para contemplar o aspecto funcional das propriedades mentais, Smith entende ser possível localizar, na percepção, uma capacidade de realizar antecipações sobre o comportamento do outro. O que podem ser antecipadas são manifestações futuras de comportamento relacionadas ao estado mental correspondente. Se eu posso perceptualmente reconhecer a dor do outro como presente em um conjunto de manifestações comportamentais, então espero determinados comportamentos e não outros. Sou capaz de distinguir, por exemplo, comportamentos relacionados a esse estado mental daqueles que não o são. Além disso, analogamente à 
percepção de objetos, as capacidades que geram antecipações poderiam ser pensadas como sensório-motoras. De acordo com a formulação de Smith,

It may be that one's perceptual presentations and anticipations 'latch onto', or match, the functional role of another's mental state. If we define mental state $M$ as that property one has if one will behave in way $B$ given input $I$, and in one's perception of another one perceptually anticipates that if I occurs then one will perceive $B$, then one's perceptual states 'latch onto' property $M$. This, I suggest, is one way of perceiving a person as instantiating mental property M.7 (SMITH, 2010, p. 741)

Um caminho diferente foi proposto por Joel Krueger (2012). Para ele, a abordagem de Smith ainda se vê de algum modo comprometida com a ideia inferencialista de que propriedades mentais são inobserváveis. Krueger defende a tese mais forte de que determinadas ações são constitutivas dos estados mentais. Assim, os estados mentais não estão meramente co-presentes. Krueger apoia-se no paradigma da mente corporificada, de acordo com o qual os processos mentais dependem em grande medida de um corpo que explora ativamente o ambiente. Nessa linha, não é possível analisar a cognição humana sem levar em conta outros elementos aos quais a mente está intimamente relacionada, notadamente o corpo e o mundo.

Um exemplo interessante é a percepção. Teóricos da cognição corporificada como Alva Noë entendem que a percepção depende do domínio das chamadas expectativas sensório-motoras (2004, p.77). Trata-se de um domínio acerca dos padrões de associação entre movimentos corporais e os efeitos que se seguem desses movimentos. Segundo a cognição corporificada, não é possível perceber sem um corpo que explora ativamente os objetos do ambiente; vale dizer, os objetos se oferecem à percepção no transcurso dessa exploração. ${ }^{8}$ A percepção não é uma espécie de fotografia, da qual o sujeito é um mero espectador, em que todos os detalhes de uma cena são capturados ao mesmo tempo. Quando percebemos visualmente, focamos nossa atenção em determinados aspectos de uma cena, enquanto deixamos os outros na sombra do campo visual. Para deslocarmos esses objetos da sombra e trazê-los à visão, temos que realizar movimentos corporais. Em

\footnotetext{
7 “Pode ser que as próprias apresentações perceptuais e antecipações 'relacionam-se', ou correspondam ao papel funcional do estado mental de outro. Se definirmos um estado mental $\mathrm{M}$ como uma propriedade tal que se alguém a possui se comportará de um modo $\mathrm{B}$ dado o input l, e se na própria percepção acerca do outro é antecipado que, se I ocorre, ele perceberá $B$, então os seus próprios estados mentais estão relacionados à propriedade M." (SMITH, 2010, p. 741)

8 Ver, sobre isso, fenômenos de "change blindness." (NOË, 2004, p.51-55).
} 
suma, aqui temos a ideia de que a ação e, portanto, o corpo, é parte do que determina a percepção. Nesse sentido, a mente vai além das fronteiras do crânio; eis a razão de se tratar de uma mente corporificada.

De que modo isso repercute na cognição social, particularmente na compreensão teórica sobre a percepção do comportamento do outro? Do lado do percipiente ou intérprete, temos a ideia de que a percepção do outro não envolve uma postura passiva. Em situações de interação social, o percipiente realiza movimentos corporais para se ajustar ao outro e isso é parte constitutiva de sua percepção. Do lado do que é percebido, o percipiente se depara com comportamentos nos quais a mente se estende. Um exemplo esclarecedor são os gestos que, em muitas ocasiões, não são meramente efeitos de processos cognitivos internos, mas sim, parte constitutiva desses processos. Como mostram as pesquisas de Susan Goldin-Meadow (2010), gestos tendem a aumentar diante da dificuldade de uma tarefa e diminuir quando a tarefa é sem esforço cognitivo. Ver gestos de outra pessoa é, nesse caso, perceber partes próprias da mente. Krueger afirma que

(...) some mental phenomena have a hybrid structure. They are states or processes that straddle both internal (neural) and external (extra-neural) operations, and are thus directly embodied within some patterns of expressive behavior. Accordingly, when we perceive behavior and expressive actions, we perceive not expressions of dispositions but rather proper parts of mental phenomena. We literally see mind in action. ${ }^{9}$

Vimos diferentes modos de mostrar que inferências muitas vezes não são necessárias para o reconhecimento de outras mentes. No entanto, não pretendo entrar no debate entre essas duas versões da percepção direta. Meu objetivo é, antes, expor um aspecto muito importante acerca da cognição social que pode exercer alguma pressão sobre a percepção direta de outras mentes, seja a respeito da tese de Smith ou de Krueger.

\footnotetext{
9 “(...) alguns fenômenos mentais têm uma estrutura híbrida. Eles são estados ou processos que cruzam operações internas (neurais) e externas (extraneurais), e são, portanto, diretamente incorporados em alguns padrões de comportamento expressivo. Consequentemente, quando percebemos o comportamento e ações expressivas, percebemos partes próprias do fenômeno mental, não expressões de disposições. Nós vemos, literalmente, a mente em ação." (KRUEGER, 2012, p. 155-156)
} 


\section{Flexibilidade cognitiva}

Pretendo apresentar algumas motivações para se adotar o inferencialismo na cognição social que são, de certo modo, neutras em relação às teorias tradicionais. De início, convém lembrar que o inferencialismo visa acomodar um aspecto muito importante da cognição social, a flexibilidade cognitiva. O agente deve ser sensível ao fato de que diferentes estados mentais podem explicar/causar um mesmo comportamento e, inversamente, diferentes movimentos corporais podem ser explicados/causados por um mesmo estado mental. Essa flexibilidade é importante porque é possível criar expectativas ou predições de comportamento sem reconhecer outras mentes. As eventuais predições ou expectativas de comportamento que aqui poderiam ocorrer seriam baseadas em associações fixas ou inflexíveis entre eventos, às quais o agente poderia estar fortemente habituado. Em que pesem os eventuais êxitos dessas expectativas e predições, nada disso sugere algum entendimento do comportamento alheio. Já o reconhecimento dos estados mentais dos outros, enquanto vai além da associação fixa entre eventos, parece demandar algum custo cognitivo. Daí que se pensou que a capacidade de atribuição de estados mentais dependa, para além da percepção, de capacidades cognitivas de ordem superior como a de realizar inferências.

Uma questão importante aqui é se a retomada recente da empatia deveria preocupar-se em acomodar, senão capacidades inferenciais, ao menos algum tipo de flexibilidade cognitiva. Por certo, muito depende do grau de flexibilidade que se tem em vista. Considere-se um alto nível de flexibilidade tal que envolve a posse de uma teoria da mente, da capacidade de imaginação, bem como de metarrepresentações. Nesse nível encontra-se justamente o conceito de inferência proposto pelas teorias tradicionais, quer seja dependente da posse de leis psicofísicas (Teoria-teoria), quer seja dependente da imaginação (Teoria da simulação). ${ }^{10}$ Tais recursos cognitivos estão muito acima de capacidades perceptuais; iriam, portanto, além do escopo da tese da empatia. Quanto a esse aspecto, proponentes da empatia lembrariam que a cognição social é um fenômeno

\footnotetext{
${ }^{10}$ De acordo com a versão modular da Teoria-teoria, a realização de inferências não demandaria raciocínio explícito, mas sim, um processamento de informação por parte de mecanismos subpessoais (NICHOLS; STICH, 2003). Assim, essa versão modular poderia ficar imune à crítica de sobrecarga cognitiva. De todo modo, a ideia de processamento subpessoal de informação não leva em conta situações externas de interação que, como veremos, afetam diretamente o reconhecimento de outras mentes. Para se levar em conta esse aspecto, é necessário ir além de uma explicação restrita a mecanismos internos ou subpessoais. Uma explicação em moldes internistas não seria, aqui, suficiente.
} 
complexo e diversificado. Há por certo situações de maior demanda cognitiva em que a percepção direta não é suficiente. Mas não existe da parte deles uma pretensão de cobrir todo o espectro da cognição social.

Entretanto, não é certo que a exigência de algum nível de flexibilidade seja simplesmente impertinente para a tese da empatia. A propósito, convém notar casos simples de interação em que a estrita percepção de expressões faciais não é suficiente para se detectar o estado mental correspondente. Por exemplo, num experimento organizado por Dailey et al. (2002) os participantes tiveram dificuldade em diferenciar uma expressão facial de repugnância de uma expressão facial de raiva. Tal ambiguidade pode ser eliminada em virtude da percepção de outros aspectos do contexto, além da expressão facial. Como reportado em outro experimento sobre percepção de expressões faciais, realizado por Wicker e colaboradores (2003), os participantes perceberam, além da expressão facial, um copo cujo interior o ator simulou inalar. Aqui, os participantes não tiveram dificuldade em detectar uma expressão de repugnância.

Não obstante, é possível notar a presença de ambiguidades mesmo nas ocasiões em que o intérprete pode rastrear perceptualmente os objetos próximos da ação. Por exemplo, pegar um copo de uma determinada maneira e, ao mesmo tempo, fixar a atenção visual para o seu interior pode tanto realizar a intenção de oferecê-lo a alguém, ou a intenção de dispensar o seu conteúdo. É possível que a intencionalidade motora que acompanha o movimento de apreensão dos dedos das mãos seja passível de ser percebida diretamente. Entretanto, aqui a finalidade de uma ação vai além do alvo a que o agente dirige seus movimentos. ${ }^{11}$ Convém notar, a esse respeito, um tipo superior de intenções, as chamadas intenções prévias. Intenções prévias podem ser dirigidas ao futuro, mesmo a um futuro próximo, a assim ser formadas independentemente dos aspectos específicos da situação que definem as possibilidades de movimentos do agente. Nesse caso, a intenção relevante para a compreensão do comportamento não é imediatamente nele detectada.

Não é, portanto, correto supor que a estrita percepção de ações fora de contexto poderia gerar o acesso a outras mentes. Insistindo no exemplo acima, considere-se que a intenção do agente seja de pegar um copo para dispensar seu conteúdo. Ao reconhecer essa intenção, outro agente se dispõe a ajudá-lo, e então faz o mesmo com os outros copos que

\footnotetext{
${ }^{11}$ Sobre isso, ver Jacob, 2008.
} 
estão em cima da mesa. A percepção estrita de um comportamento fora de contexto, como simplesmente a de um movimento de apreensão de um copo, sem identificá-lo como parte de um conjunto de comportamentos que pode levar à realização de uma intenção que não se revela à primeira vista, não permite coordenar ações com o agente em questão.

É bem certo que o agente pode ter outras intenções em mente que não se revelam para o intérprete. Por exemplo, ele pode ter a intenção de limpar a mesa porque no dia seguinte receberá a visita de um parente que não vê há muito tempo. Talvez o intérprete não tenha que reconhecer essa intenção para coordenar ações com esse agente; basta que o intérprete reconheça a intenção de limpar a mesa. Entretanto, sem ir além da estrita percepção do comportamento, não parece possível detectar qualquer mentalidade no comportamento do outro, de maneira a permitir entrar em um episódio de coordenação de ações.

Esses exemplos nos mostram as circunstâncias em que a estrita percepção de expressões faciais ou, de maneira geral, do comportamento, não é suficiente para se reconhecerem estados mentais. O que se exige nesses casos é o reconhecimento de que uma mesma expressão facial, ou um mesmo movimento corporal, pode expressar diferentes estados mentais tendo em vista diferenças entre as situações. Em suma, se a estrita percepção de expressões faciais, ou mesmo a percepção de ações, subdetermina os estados mentais, exige-se da empatia a acomodação de algum nível de flexibilidade cognitiva. Assim temos boas razões para afirmar que o intérprete tem que ir além da estrita percepção do comportamento para reconhecer outras mentes. Esse ponto parece, em geral, bem aceito pelos proponentes da empatia, como veremos abaixo. Mas note-se que já está aí embutida alguma flexibilidade, a saber, a sensibilidade ao contexto. A questão que se coloca para a empatia é como acomodar essa flexibilidade. $E$, dado que essa corrente abre mão de inferências, a questão que se coloca é como essa flexibilidade pode ser acomodada no domínio da percepção.

\section{Percepção direta em contexto}

Proponentes da empatia não teriam qualquer problema em mostrar que a percepção de objetos não entra em conflito com a percepção do contexto. Eles lembrariam que a 
abordagem fenomenológica afirma justamente que não é possível perceber objetos fora de contexto. Como coloca Merleau-Ponty:

O 'algo' perceptível está sempre no meio de outra coisa, ele sempre faz parte de um 'campo'. Uma superfície verdadeiramente homogênea, não oferecendo nada para se perceber, não pode ser dada a nenhuma percepção. (...) Um dado perceptivo isolado é inconcebível, se ao menos fazemos a experiência mental de percebê-lo. (MERLEAU-PONTY, 2006, p. 24-25)

De maneira análoga, a percepção do comportamento do outro é sempre a percepção de um agente situado em um contexto particular. É importante ressaltar que a posição fenomenológica volta-se para as situações ordinárias de interação, justamente o lugar em que o conceito de empatia parece ter aderência. Afirma-se que a empatia é fecunda para esclarecer a sensibilidade a outras mentes nessas situações. Dado o caráter fluente dessas interações, os agentes não precisam se engajar em um processo explícito de compreensão. Aqui o entendimento mútuo está submetido ao propósito de coordenar ações. A imagem sobrecarregada de um observador passivo e externo às interações, que procura fornecer explicações acerca do comportamento de outrem, não parece adequada. Uma imagem mais adequada é a do participante de interações que percebe diretamente os estados mentais dos outros. A percepção do comportamento é, assim, enriquecida pela percepção do contexto: o rastreamento de aspectos contextuais contribui para reconhecimento de outros estados mentais.

Além disso, é muito importante notar que nas situações ordinárias de interação esse contexto é compartilhado. Esse traço é prototipicamente ilustrado pelas situações de atenção conjunta. Nessas situações, os agentes percebem os mesmos aspectos de uma situação e estão conscientes dessa situação compartilhada. Que os agentes possam compartilhar situações permite uma sensibilidade às informações acerca dos estados mentais dos outros que de algum modo se fazem presentes nas estruturas do contexto, tais como objetos, gestos entre outras expressões corporais. Enfim essas situações aliviam a carga cognitiva que poderia aparecer para um intérprete que, fora de um contexto compartilhado, precisaria suportar para acessar a mente do outro - como representar os estados mentais dos outros mediante metarrepresentações. De acordo com Zahavi, 
(...) we shouldn't overlook the fact that our encounter with another is never an encounter with an entity outside a specific situation, but with an agent in the middle of a pragmatic context that throws light on the intentions of that agent. If, on a football field, I see you run towards a football, my understanding of your intentions is obviously facilitated by the fact that I can also see the football and the football field, and the actions that they afford (...) When seeking to understand the why of the other's actions, it is always productive to focus on the shared motivational context, since the cues it provides can offload part of the cognitive burden of having to make inferences about the hidden mental states of the other. ${ }^{12}$

Precisamos, contudo, de mais explicações para mostrar que situações de copresença podem atender a uma demanda de flexibilidade pertinente à estabilidade das interações. Como mostra a diferença entre alvo e finalidade, mesmo em situações compartilhadas pode ocorrer que o estado mental do outro, cuja detecção é relevante para a coordenação de ações, não seja imediatamente perceptível. Deve-se mostrar mais claramente como é possível, pela percepção, detectar estados mentais que, embora não sejam imediatamente acessíveis em um dado momento, devem ser identificados como parte crucial do que gera a fluência de interações ordinárias.

Uma resposta é levar em conta interações estendidas no tempo, em particular, a capacidade de os agentes lidarem, além da interação ocorrente, com situações passadas e situações futuras. Um problema é que situações passadas e situações futuras não parecem estar disponíveis à percepção dos agentes. Assim, ao que parece, os agentes em coordenação de ações devem partir da situação presente e realizar inferências que permitem tanto manter o rastro do que já ocorreu, quanto antecipar situações futuras. Como essa flexibilidade das interações poderia ocorrer sem a realização de inferências?

A tradição fenomenológica nos oferece recursos para explicar como os agentes conseguem interagir ao longo do tempo sem realizar inferências. Para essa tradição, particularmente Husserl e Merleau-Ponty, situações passadas e futuras estão envolvidas na

\footnotetext{
12 "(...) nós não devemos esquecer o fato de que nosso encontro com o outro nunca é um encontro com uma entidade fora de uma situação específica, mas com um agente no interior de um contexto pragmático, que lança luz sobre suas intenções. Se, em um campo de futebol, eu vejo você correr em direção à bola, meu entendimento de suas intenções é obviamente facilitado pelo fato de que eu posso também ver a bola e o campo de futebol, e as ações que eles possibilitam (...). Quando se procura entender o motivo das ações dos outros, é sempre produtivo focar no contexto motivacional compartilhado, uma vez que as pistas que ele fornece aliviam, parcialmente, a carga cognitiva presente na realização de inferências sobre os estados mentais escondidos do outro." (ZAHAVI, 2011, p. 551-552)
} 
percepção presente sob a forma de retenções e protensões. Retenções, impressões ocorrentes e protensões são partes inseparáveis da percepção enquanto ação que se inscreve no tempo. Ao perceber um objeto, o agente mantém o rastro do que foi percebido no momento anterior e antecipa o que resultará de sua exploração perceptual. Retenções e protensões estão no horizonte ou na circunvizinhança do campo perceptual. Tais aspectos não são, portanto, visíveis. O agente não os representa de forma explícita; desse modo, por exemplo, a retenção distingue-se da memória e a protensão não envolve uma imaginação acerca do futuro. Nessa linha, Merleau-Ponty afirma que retenções e protensões

não partem de um Eu central, mas de alguma maneira de meu próprio campo perceptivo, que arrasta atrás de si seu horizonte de retenções e por suas protensões morde o porvir. (MERLEAU-PONTY,2006, p.558)

Retomando o exemplo acima, se a apreensão do copo fosse um movimento isolado no tempo, a percepção não seria suficiente. Nesse caso, talvez inferências fossem necessárias. Mas não é isso que tipicamente ocorre. Note-se que, nas interações ordinárias, tanto a percepção quanto o comportamento do outro são fenômenos temporalmente estendidos. Como já foi colocado, no curso da interação o intérprete realiza um conjunto de movimentos corporais visando se ajustar ao outro, como sincronização de movimentos, algo que facilita o seu entendimento. ${ }^{13} \mathrm{E}$ o que ele percebe é a co-relação dinâmica entre o comportamento do outro e os objetos salientes para esse comportamento. Dado que essa percepção envolve manter o rastro do passado e antecipar implicitamente o futuro, o agente poderia detectar estados mentais não revelados à primeira vista. A intenção relevante se desvelaria no próprio comportamento e no interior da situação interativa em que ocorre. Não seria necessário, portanto, um passo inferencial entre ver um agente se comportando de determinada maneira e reconhecer o estado mental relacionado a esse comportamento. Enfim, a abordagem fenomenológica de antecipações implícitas tem o mérito de respeitar interações ordinárias. Trata-se de uma explicação que parece adequada ao que se exige para o engajamento nessas interações fluentes.

Aqui temos uma forma de acomodar a flexibilidade no nível da percepção de outras mentes. Nas interações, os agentes são perceptualmente sensíveis às situações temporalmente estendidas de interação, nas quais é possível detectar estados mentais que

\footnotetext{
13 Sobre isso, ver De Jaegher, 2009.
} 
se expressam de diversos modos no comportamento. No que se segue, veremos se essa abordagem da empatia é suficiente para gerar uma coordenação de ações de maneira estável. A questão que vai nos ocupar é se essa análise contempla um grau suficiente de flexibilidade para explicar os episódios de coordenação de ações.

\section{Modos indiretos de interação social}

Na medida em que a tese fenomenológica da empatia leva em conta antecipações implícitas, ela talvez pudesse atender ao tipo de flexibilidade que temos visto. No entanto, é importante notar que essa tese apoia-se na ideia de que, em situações de coordenação de ações, os estados mentais dos agentes estão diretamente conectados com o ambiente. Esse aspecto esclarece o papel da empatia nessas situações: os agentes coordenam ações baseados na capacidade de relacionar diretamente os estados mentais presentes no comportamento dos outros aos objetos da situação. Para os estados mentais que não se revelam imediatamente no comportamento, a ideia é mostrar que ao longo do curso da interação, eles estariam igualmente disponíveis de forma direta à percepção do intérprete.

Entretanto, é justamente o aspecto temporalmente estendido da coordenação de ações que demanda dos agentes a capacidade de dar um passo atrás no curso da interação e considerar diferentes maneiras de ajuste mútuo. Nessas situações, eles precisam refinar seu acesso à mente do outro. Para isso, devem ir além da sua percepção direta entre o comportamento do outro e os objetos da situação. Essa maior fineza do acesso a outras mentes aponta para a necessidade de se levar em conta modos indiretos de interação social. Além da nossa primeira exigência de flexibilidade, que se coloca enquanto percepção do comportamento dentro de um contexto, a capacidade de dar um passo atrás é o segundo e mais importante nível de flexibilidade que a posição fenomenológica da empatia deve acomodar.

Nesse ponto da argumentação, pode parecer que é sempre possivel introduzir mais elementos nas situações ordinárias de maneira a limitar o alcance da explicação da abordagem fenomenológica da empatia. Por certo, não é meu objetivo traçar limites claros sobre o que pertence a essas interações. De qualquer modo, pretendo, no que se segue, expor alguns aspectos fortemente presentes em interações comuns entre humanos: vou me concentrar nas situações em que essa maior fineza está ligada ao reconhecimento da 
perspectiva do outro. São situações em que não é suficiente detectar quais objetos do contexto o agente dirige suas ações, mas também como esses objetos se mostram a partir da perspectiva do outro.

Um agente capaz de assumir perspectivas ou pontos de vista é aquele para o qual os objetos se mostram de determinadas formas - que se alteram conforme a posição do agente no espaço. Perceber os objetos a partir de perspectivas permite ajustar-se de diferentes maneiras aos objetos, corrigir e escolher movimentos apropriados para manipulá-los. Ora, muitas situações de coordenação de ações exigem que esses diferentes modos de acessar os objetos sejam levados em conta. Nessas situações, não é suficiente que cada um perceba que o outro veja o mesmo objeto. Além disso, os agentes devem ter presente que um mesmo objeto aparece de diferentes modos, muitas vezes opostos, para ele e para o outro. Isto é, eles devem confrontar suas perspectivas mútuas. Vejamos duas situações ordinárias em que essa exigência aparece.

No primeiro caso, considere-se uma situação simples em que os agentes precisam passar uma mesa por um vão estreito de uma porta, de tal maneira que a primeira tentativa é realizada sem sucesso. Nessa situação, não é suficiente que ambos vejam a mesma mesa e que compartilhem atitudes em relação a ela. Para coordenar as suas ações, eles devem levar em conta as diferentes perspectivas que cada um tem acerca da mesa. Para realizarem novos ajustes e reorganizarem a coordenação, eles precisam ir além de perceber os objetos aos quais as atitudes estão relacionadas.

Evidentemente, não se trata de uma tarefa em que os agentes precisam se engajar em algum tipo de compreensão mais profunda acerca do modo como o outro vê. Entretanto, não é evidente como eles podem fazer isso com base em uma experiência perceptual direta acerca dos outros. Para ser sensível à perspectiva do outro, cada um dos agentes precisa ir além da percepção compartilhada dos objetos. Note-se, ademais, que não se trata de um reconhecimento irrelevante para episódios interativos de co-presença. 0 que se exige é a sensibilidade à diferença entre perspectivas de $2^{\circ}$ ordem (o modo como o outro vê). ${ }^{14}$ Essa sensibilidade é crucial para que os agentes consigam se reajustar em relação ao outro.

\footnotetext{
${ }^{14} \mathrm{~A}$ sensibilidade ao modo como o outro vê os objetos em um contexto requer mais esforço cognitivo do que simplesmente detectar os objetos que se colocam no campo visual do agente. Nesse segundo caso, trata-se simplesmente de uma sensibilidade à perspectiva de $1^{\circ}$ ordem: o agente é capaz de diferenciar os objetos da percepção do agente daqueles que não são. Para isso, é suficiente a capacidade de seguir o olhar.
} 
Essa sensibilidade é, em particular, parte essencial da coordenação de ações a partir de estados mentais como crenças. O que importa aqui não é somente o que o agente acredita, mas sobretudo como acredita - que é parcialmente fixado pelo seu ponto de vista em relação ao mundo. Por exemplo, considere-se a crença de um agente que está diante de um copo d'água, seu desejo de matar a sede e a ação de alcançar o copo para realizar o seu desejo. Note-se que parte do que determina o conteúdo da crença é a sua experiência perceptual com o copo. O agente vê o copo em uma determinada posição e orientação com relação ao seu corpo. Assim o agente acredita não somente que há um copo em cima da mesa, mas também que há um copo diante dele. Essa sua crença é parte do que determina seus movimentos; esclarece por que ele realizou determinados movimentos e não outros. Para coordenar ações com esse agente a partir do reconhecimento de sua crença, é necessário ir além do que ele percebe e acessar o modo como o objeto aparece do seu ponto de vista. Isso é crucial para que o intérprete seja capaz de se reorganizar em relação ao outro, buscar novos ajustes, realizar antecipações, promover correções e assim por diante.

Nesse passo, uma comparação entre humanos e chimpanzés pode vir a calhar. Em um importante experimento, os primatologistas Hare, Call e Tomasello (2001) mostraram que chimpanzés são capazes de diferenciar uma pessoa perceptualmente ciente de uma pessoa perceptualmente ignorante. Por exemplo, um chimpanzé subordinado evita pegar um alimento se ele nota a presença do dominante. Mas não tem qualquer problema em fazê-lo se ele notar a presença de uma barreira impedindo o acesso visual do dominante ao alimento. Assim chimpanzés parecem ser sensíveis, em alguma medida, aos objetos que estão no campo visual do outro (perspectiva de $1^{\circ}$ ordem). Eles também parecem identificar que um competidor que está em uma relação perceptual direta com esses objetos se comportará de maneira diferente do outro que não se encontra nesta situação. Dessa forma, chimpanzés são sensíveis não somente aos objetos que outros veem, mas também ao fato de que o que veem influencia, de algum modo, as suas ações. Ou seja, chimpanzés parecem ter algum domínio sobre a relação entre percepção e ação. ${ }^{15}$ Entretanto, não há qualquer

\footnotetext{
${ }^{15}$ Essa evidência tem sido reafirmada por Tomasello e colaboradores em artigos e experimentos mais recentes: All of the evidence (...) suggests that chimpanzees understand both the goals and intentions of others as well as the perception and knowledge of others. Moreover, they understand how these psychological states work together to produce intentional action; that is, they understand others in terms of a relatively coherent perception-goal psychology in which the other acts in a certain way because she has certain goals of how she
} 
evidência de que chimpanzés sejam sensíveis ao modo como os objetos se mostram da perspectiva do outro, sobretudo nos casos em que o outro tem uma perspectiva oposta à perspectiva dele. Essa constatação pode, de resto, ser parte da explicação sobre a ausência de reconhecimento de crenças em chimpanzés. ${ }^{16}$

De maneira talvez mais evidente, modos flexíveis de interação social são necessários para haver sensibilidade a crenças falsas dos outros. Quanto a esse tipo de sensibilidade, não basta reconhecer que o outro ignora perceptualmente uma situação, mas sim, que ele pode estar mal informado acerca dela e, sobretudo, agir com base nessa crença falsa. $O$ agente deve ser sensível aos seguintes aspectos: (i) há uma situação compartilhada entre ele e o outro; (ii) o outro tem uma perspectiva diferente dele acerca dessa mesma situação e, além disso, uma perspectiva falsa. Isso requer do agente a capacidade de inibir o que está diretamente disponível à sua percepção, nomeadamente, os objetos da situação aos quais a crença do outro estaria diretamente relacionada se fosse verdadeira. Para detectar o que o outro falsamente acredita, o agente deve ser capaz de suspender um estado mental de suas relações diretas com o mundo.

A propósito, considere-se a diferença entre, por um lado, reconhecer perspectivas que, embora diferentes, podem coexistir acerca de um mesmo objeto, e, por outro lado, reconhecer perspectivas mutuamente excludentes acerca de um mesmo objeto. No segundo caso, que envolve crença falsa, o agente deve ser capaz de contrastar as perspectivas. Para descobrir que o outro tem uma perspectiva falsa acerca de um objeto, o agente teria que ter também presente a perspectiva verdadeira. No entanto, note-se que a perspectiva falsa não é um evento disponível à percepção do outro. Trata-se de um evento contrafactual; para acessá-lo, o agente precisa lançar mão de recursos cognitivos que operam em um modo off-line: ele precisa dar um passo atrás em relação à interação e se engajar em um modo indireto de cognição social. Para essa tarefa, capacidades cognitivas extraperceptuais, como capacidades inferenciais, devem entrar em ação.

wants the world to be. "Toda evidência sugere que chimpanzés entendem tanto fins e intenções, quanto a percepção e o conhecimento dos outros. Ademais, eles entendem como esses estados psicológicos trabalham juntos para produzir a ação intencional; i.e., entendem os outros em termos da psicologia da coerência entre percepção e finalidade, em que os outros agem de certa maneira porque desejam que o mundo seja desse modo." (TOMASELLO et al., 2008, p. 191)

${ }^{16}$ Há um amplo consenso entre primatologistas acerca do fato de que chimpanzés são insensíveis a crenças dos outros. A explicação não é somente ausência de linguagem ou de uma teoria da mente dotada de metarrepresentações, mas também, justamente a insensibilidade a perspectivas de $2^{\circ}$ ordem. Ver, sobre isso, Moll ;Tomasello, 2013. 
Aqui aparece, a meu ver, um limite importante para a abordagem fenomenológica, particularmente ao argumento de que no domínio perceptual, que inclui antecipações implícitas, é possível ir além da situação ocorrente e levar em conta outras situações. Notese que o argumento que apoia antecipações implícitas é, no caso, o que pode ser antecipado dada nossa habituação com os objetos e eventos do mundo. Eis Merleau-Ponty novamente acerca de protensões:

Nosso porvir não é feito apenas de conjecturas e de divagações. Adiante daquilo que vejo e daquilo que percebo, sem dúvida não há mais nada de visível, mas meu mundo continua por linhas intencionais que traçam antecipadamente pelo menos o estilo daquilo que virá. (MERLEAU-PONTY, 2006, p. 557-558)

Essa argumentação pode esclarecer interações ordinárias do seguinte modo: dada uma interação regular, retenções e protensões respondem pela estabilidade e fluência. No entanto, quando há uma quebra nessa regularidade, que ocorre diante de expectativas não cumpridas, ou mudanças inesperadas no curso da interação, como de resto ilustra o caso em que um dos participantes tem uma crença falsa, outros recursos cognitivos parecem necessários.

\section{A Hipótese das Práticas Narrativas}

As considerações precedentes apontam para a necessidade de uma explicação mais robusta sobre os modos indiretos de cognição social. Um desdobramento recente da tese fenomenológica, a chamada "hipótese das práticas narrativas", pretende lidar com esse explanandum. De acordo com Shaun Gallagher e Daniel Hutto (2008), determinadas narrativas, apresentadas sob a forma de estórias ou conversas, incluem uma sequência de eventos temporalmente ordenados tal que, entre outras coisas, explica o comportamento das personagens. Importa notar que o ato de contar estórias, assim como as conversas, ocorre tipicamente em contextos interativos: adultos e crianças compartilham um conjunto de reações suscitadas pelo desenrolar da estória. Essas estórias seriam, portanto, potencialmente fecundas para o desenvolvimento de capacidades cognitivas sociais.

Com efeito, Gallagher e Hutto sugerem que as narrativas seriam pertinentes para o desenvolvimento da compreensão de estados mentais de ordem superior como crenças, 
dado que estabeleceriam as situações em que tipicamente esses estados mentais estão ancorados. Mediante a exposição reiterada a essas narrativas, a criança seria habituada a compartilhar a sua atenção com o adulto em relação a conceitos mentais, como desejo, crença e assim por diante. Com o tempo, ela mesma se tornaria capaz de explicar o comportamento do outro através desses termos, vale dizer, através de razões. Esse aspecto poderia explicar o fato de ela conseguir atribuir estados mentais a personagens com relativa facilidade, como no caso da literatura ficcional que envolve alguma psicologia comum.

Teria essa hipótese um alcance explicativo suficiente para lidar com a flexibilidade na cognição social? À primeira vista, a proposta parece interessante porque permite compreender a flexibilidade sem alto custo cognitivo. Ademais, trata-se de uma proposta que contempla contextos interativos. No entanto, a hipótese das práticas narrativas deveria mostrar, precisamente, quais capacidades se encontram em operação na compreensão de estados mentais superiores. Embora Gallagher e Hutto não sejam claros quanto a esse ponto, parece razoável supor que os agentes poderiam perceber esses estados mentais de forma direta, ou não inferencial. Por exemplo, a exposição reiterada a situações de crença falsa poderia eximir o agente de realizar de inferências.

No entanto, como temos visto, que um agente tenha crenças falsas não parece ser uma informação perceptualmente disponível ao outro. Tal como coloca Lisa Zunshine, o conjunto de habilidades que se pode adquirir mediante a exposição a contextos ficcionais é apenas uma parte da explicação sobre como leitores atribuem estados mentais a personagens. Segundo ela, teorias cognitivas acerca da literatura devem aprofundar a cognição humana e dialogar com a psicologia cognitiva. ${ }^{17}$ No exemplo proposto por Zunshine, considere as diferentes interpretações possíveis acerca do comportamento hesitante do personagem Peter Walsh, do romance Mrs. Dalloway de Virgínia Wolf, em sua visita inesperada à personagem Clarissa Dalloway. ${ }^{18}$ Nesse caso, como em tantos outros, os

\footnotetext{
17 To understand what enables most of us to constrain the range of possible interpretations, we may have to go beyond the explanation that evokes our personal reading histories and admit some evidence from our evolutionary history. "Para se entender o que permite, a muitos de nós, restringir o conjunto de possíveis interpretações, é preciso ir além da explicação que evoca nossa leitura pessoal de estórias e admitir alguma evidência da nossa história evolucionária." (ZUNSHINE, 2006, p.10)

$18 \mathrm{Na}$ passagem em questão, Peter Walsh, em uma visita inesperada a Clarissa Dalloway, exibe um comportamento trêmulo e hesitante; mas não é claro se o seu comportamento é causado pela excitação de rever seu antigo amor, ou se causado pelo seu mal de Parkinson. Vale notar que as relações entre cognição social e literatura são muito complexas, de tal modo que não é possível tratá-las aqui no pormenor sem me
} 
leitores precisam aprofundar o acesso à mente das personagens, algo que, por certo, vai além da percepção.

Vamos retomar a tese da empatia. O problema é a dificuldade de esclarecer a percepção direta do modo como o outro acessa o mundo. Do que vimos, segue-se que essa não parece ser uma informação perceptualmente disponível na relação direta entre estados mentais, comportamento e contexto. Para reconhecer perspectivas diferentes, um agente precisa aprofundar em alguma medida a relação entre estados mentais e mundo, e, no fim das contas, reconhecer que estados mentais podem se desconectar das situações ocorrentes - como no caso de crenças falsas. Trata-se justamente da capacidade de dar um passo atrás no curso de uma interação. Além da situação compartilhada, exige-se de cada um dos agentes a capacidade de contrastar sua própria perspectiva com a perspectiva da outra pessoa. A percepção dos elementos da situação não é aqui suficiente; parece somente ser parte de um processo inferencial de extrair informações acerca do que se passa na mente do outro. Tais informações, que garantem a estabilidade de situações ordinárias, não estão explícitas no comportamento e nos objetos da situação. Portanto, a estabilidade das interações, justamente o aspecto central da abordagem fenomenológica, não é garantida pela percepção direta do comportamento.

Enfim, uma maior fineza no reconhecimento de outras mentes é parte essencial da coordenação de ações a partir de estados mentais como crenças. Como temos visto, o que importa aqui não é somente o que o outro acredita, mas como ele acredita. Para coordenar ações com um agente a partir de sua crença, é necessário ir além do que ele percebe e acessar o modo como o objeto aparece do seu ponto de vista. Isso é crucial para que o intérprete seja capaz de se reorganizar em relação ao outro, buscar novos ajustes, promover correções e criar expectativas de comportamento. Trata-se, em suma, de um acesso inferencial a outras mentes. Esse acesso deve ser levado em conta na análise de interações temporalmente estendidas, tal como se propõe a abordagem fenomenológica da empatia.

desviar dos propósitos do artigo. De todo modo, a análise que ofereço aqui pode ser fecunda para um tratamento futuro mais aprofundado sobre esse tema. 


\section{Conclusão}

A abordagem fenomenológica da empatia tem o mérito de se voltar para situações ordinárias de interação, justamente o lugar em que a cognição social se ancora. Nessas situações, de fato, não percebemos meros movimentos corporais desprovidos de direcionalidade. Para isso, é suficiente que sejamos capazes de detectar, pela nossa percepção, os estados mentais diretamente relacionados aos objetos. Mas, como vimos, é possível detectar essa relação sem compreender perspectivas de $2^{\circ}$ ordem. Por certo, a abordagem fenomenológica nos alerta a respeito do risco de sobrecarregar os agentes, algo que descaracterizaria a fluência das interações. Por esse motivo, não se trata aqui simplesmente de propor uma retomada do conceito de inferência tal como postulado pelas teorias tradicionais. No entanto, o problema é que, sem aprofundar nosso acesso à mente do outro, não parece possível descobrir que ele pode ter um ponto de vista diferente do nosso. Essa capacidade, por sua vez, é crucial para se levar em conta a flexibilidade que, como vimos, é um traço essencial das nossas interações ordinárias.

Uma questão que se coloca para além dos limites do presente artigo é, então, de que forma capacidades cognitivas como capacidade inferenciais podem aderir a situações ordinárias de coordenação. Talvez seja possível pensar em um conceito de inferência que não seja cognitivamente tão exigente a ponto de não fazer justiça ao que ocorre com os agentes comuns em interação. Nem um conceito que seja insensível à influência dos aspectos externos, i.e., das situações de interação elas mesmas, que influenciam a cognição dos agentes. Vale dizer, um conceito de inferência não explorado pela Teoria da Simulação, tampouco pela Teoria-teoria. Seja como for, não parece haver boas razões para se renunciar a uma ideia inferencialista da cognição social.

\section{Referências}

DAILEY, M., COTRELL,G., PADGETT, C., ADOLPHS, R. Empath: a neural network that categorizes facial expressions. Journal of Cognitive Neuroscience. 14-8: 1158-1173, 2002.

DE JAEGHER. Social understanding through direct perception ? Yes, by interacting. Consciousness and Cognition 18: 535-542, 2009. 
DE VIGNEMONT, F. Knowing Other People's Mental States as if They Were One's Own. In. Handbook of Phenomenology and Cognitive Science. Springer, 283-299, 2010.

GALLAGHER, S. Direct Perception in the intersubjective context. Consciousness and Cognition 17: 535-543, 2008.

GALLAGHER, S., HUTTO, D. Understanding others through interaction and narrative practice. In. The Shared Mind. Oxford Press, 2008.

GOLDIN-MEADOW, S. Action's Influence on Thought: The case of gesture. Perspectives on Psychological Science. 5 (6), p. 664-674, 2010.

GOLDMAN, A. Simulating minds: The philosophy, psychology, and neuroscience of mindreading. Oxford: Oxford University Press, 2006.

HARE, B.; CALL, J; TOMASELLO, M. Do chimpanzees know what conspecifics know? Animal Behaviour, 61, 139-151, 2001.

HARE, B., TOMASELLO, M. Chimpanzees are more skillful in competitive than in cooperative cognitive tasks. Animal Behaviour, 68, 571-581, 2004.

JACOB, P. The Direct-Perception Model of Empathy: a Critique. Review of Philosophy and Psychology, 2, 519-540, 2011.

KRUEGER, J. Seeing mind in action. Phenomenology and Cognitive Science, 11, p. 149-173, 2012.

MERLEAU-PONY, M. Fenomenologia da Percepção. Martins Fontes, 2006. (Publicado pela primeira vez em 1945)

MOLL, H.; TOMASELLO, M., Why don't apes understand false beliefs? In. Navigating the social world: What infants, children, and other species can teach us. Oxford University Press. p. 81-87, 2013.

NICHOLS, S; STICH, S. Mindreading. An integrated account of pretense, self-awareness, and understanding other minds. Oxford Press, 2003.

NOË, A. Action in Perception. Cambridge: MIT Press, 2004.

PACHERIE, E. La dynamique des intentions. Dialogue, XLII, 3: p. 447-480, 2003.

SCHELER, M. The nature of Sympathy. Routledge, 1954.

SHAPIRO, L. Embodied Cognition. Mit press, 2007.

SMITH, J. Seeing Other People. Philosophy and Phenomenological Research. Vol. LXXXI n.3, p. 731-748, 2010. 
STUEBER, K. Rediscovering Empathy: Agency, Folk Psychology and Human Sciences. MITPress, 2006.

TOMASELLO, M.; CALL, J.. Does the chimpanzee have a theory of mind ? 30 years later. Cell Press, p. 187-192, 2008.

WICKER, B., KEYSERS, C., PLAILLY, J. ROYET, J.P., GALLESE, V., RIZZOLATTI, G. Both of us disgusted in my insula: the common neural basis of seeing and feeling disgust. Neuron 40: p. $655-664,2003$.

ZAHAVI, D. Empathy and Direct Social Perception: A Phenomenological Proposal. Review of Philosophy and Psychology. 2: 541-558, 2011.

ZAHAVI, D. OVERGAARD. Empathy without Isomorphism: A Phenomenological Account. In. Empathy: From Bench to Bedside. Mit Press, p. 3-21, 2012.

ZUNSHINE, L. Why we read fiction. Theory of mind and the novel. The Ohio State University, 2006. ' Daniel DE LUCA-NORONHA é doutor em Filosofia pela UFMG. Atualmente é bolsista de pós-doc pelo
PNPD-CAPES. Email: deluca.11@gmail.com 